\title{
Reflexões fenomenológico-existenciais para a clínica psicológica em grupo
}

\section{Phenomenological-existential reflections for psychological clinic in group}

\author{
Ana Tereza Camasmie* \\ Universidade Federal Fluminense - UFF, Niterói, Rio de Janeiro, Brasil \\ Roberto Novaes de Sá** \\ Universidade Federal Fluminense - UFF, Niterói, Rio de Janeiro, Brasil
}

\begin{abstract}
RESUMO
A modalidade grupo na clinica psicológica parece habitar um lugar instável nas práticas clínicas, uma vez que sua validade e legitimação são questionadas principalmente em comparação com a modalidade individual. E por estarmos imersos em uma perspectiva contemporânea de privilegiar métodos que afirmem tudo o que é da ordem do individual e da autossuficiência, essa prática clinica pode restringir-se apenas a espaços de grandes demandas de atendimento psicológico, correspondendo à lógica da produtividade e comprometendo sua finalidade clínica. A fim de afirmar essa modalidade clínica na abordagem fenomenológico-existencial, este artigo pretende aproximar a fenomenologia hermenêutica de Martin Heidegger à experiência clínica a fim de refletir sobre dois aspectos importantes do cotidiano psicoterápico: o diálogo clínico e o vínculo psicoterapêutico, diferenciando das abordagens que partem de teorias essencialistas sobre grupos.
\end{abstract}

Palavras-chave: Psicoterapia, Grupo, Fenomenológico-existencial, Clínica, Martin Heidegger.

\begin{abstract}
The group modality in the psychologic clinic seems to inhabit an instable place in the clinical practice, since its validation and legitimacy are questioned mainly in comparison with the individual modality. Due to being overwhelmed by the contemporary perspective of granting privilege to methods that affirm everything that concerns the individual and the selfsufficiency, this clinical practice may restrain itself to spaces of great demands of psychological treatment, corresponding to the productivity logic and compromising its clinical purpose. Aiming at affirming this clinical modality in the phenomenological-existential approach, this article means to bring the hermeneutic phenomenology of Martin Heidegger closer to the clinical experience in order to reflect upon two important aspects of the psychotherapeutic routine: the clinical dialogue and the psychotherapeutic link, differentiating it from the approaches that are based in essentialist theories about groups.
\end{abstract}

Keywords: Psychotherapy, Group, Phenomenological-existential, Clinic, Martin Heidegger. 


\section{Introdução}

A modalidade grupo na clínica psicológica parece habitar um lugar instável nas práticas clínicas. Não é raro que sua validade e legitimação sejam questionadas principalmente em comparação com a modalidade individual, ou que sua presença seja requisitada somente como recurso para atender a grandes demandas de atendimento psicológico em instituições. Esse questionamento geralmente aparece através da tentativa de validá-la segundo vários parâmetros, tais como: superficial/profundo, eficácia/eficiência, indivíduo/coletivo, conteúdo/processo, particular/institucional, o que mantém a psicoterapia de grupo no lugar em questão, onde seu contorno requer constante reconfiguração.

No entanto, diversas teorias psicológicas que se propõem a sustentar a clinica grupal, têm tido a preocupação de poder responder a esses questionamentos oferecendo argumentos que legitimem essa prática. Ainda assim, parece faltar uma interrogação sobre o fundamento dessas questões pertinentes, por estas se tratarem de ordem essencialista e, portanto, requererem respostas que atendam a essa mesma perspectiva. Por essencialista entende-se tomar o grupo como objeto em si, e, portanto, dotado de permanência que possibilite teorizações universais. Talvez seja pela falta de reflexão sobre esses fundamentos, e, portanto, de que concepção sobre grupo se está partindo para questionar, que grande parte da literatura sobre grupos se atenha e se dedique a responder objetivamente.

Pensar numa prática clínica que busque seus fundamentos na filosofia da existência requer um caminho de reflexão em que se abandonem concepções gerais sobre grupos para que se possa aproximar ao que é mais próprio à experiência clinica em grupo.

Para o filósofo Martin Heidegger (2001, p. 211), toda vez em que se procura o fundamento de algo no sentido genético-causal afasta-se do seu entendimento mais próprio, pois esta perspectiva parte de valores prévios à própria coisa. $O$ autor sugere então, que a busca pelo fundamento deveria ser a procura pela sua condição de possibilidade de ser. Tomar o fundamento como aquilo em que repousa tudo o que se dá a mostra, essa é a proposta heideggeriana a qual se pretende aproximar para refletir sobre esta prática clínica. Busca-se assim realizar um diálogo da clínica em grupo com a fenomenologia existencial, a fim de evidenciar seus desdobramentos no cotidiano psicoterápico.

\section{Aproximações heideggerianas para a questão do vínculo}

Segundo Duarte (2002, p. 157), críticos de Martin Heidegger, como Richard Wolin, Lawrence Vogel, Jurgen Habermas e outros, 
costumam apontar em Ser e Tempo a falta de preocupação do autor sobre a questão da alteridade. Tal posicionamento teri sugerido que a obra tenha então desconsiderado a questão da ética, em favor de um solipsismo existencial, na medida em que Heidegger se refere a possibilidades existenciais que à primeira vista podem parecer propriedades, ou finalidades do ser-aí, tais como por exemplo, quando afirma que "a angústia singulariza e abre o ser-aí como solus ipse" (HEIDEGGER, 1998a, p. 252), ou que o ser-aí pode "recuperarse a si-mesmo", ou "encontrar seu ser mais próprio".

Por outro lado, não são poucos os artigos que se têm publicado sobre o tema (NUNES, 2001; BARATA, 2009; DUARTE, 2000 e 2002), na tentativa de evidenciar as pistas que contrariam essa visão. E estas pistas não estão escondidas, a começar pelo quarto capitulo de Ser e Tempo, que diz respeito à co-existência dos outros, mas também se encontram dispersas e entremeadas em toda a obra. E embora Heidegger não tenha escrito um texto especifico sobre "os outros", isso não significa que a alteridade seja irrelevante em seu pensamento. Quem sabe não seria justamente o contrário? Pela impossibilidade fenomenológica de se separar eu e outro, já que o ser-aí é ser-no-mundo com outros, não faria sentido Heidegger se dedicar ao "outro" como algo independente ou que pudesse ser analisado fora da perspectiva do si e do mundo. Nas palavras de Heidegger: "... de início, um mero sujeito não 'é' e nunca é dado sem mundo. Da mesma maneira, também de início, não é dado um eu isolado sem os outros" (HEIDEGGER,1998a, p. 167). E ainda, "O seraí se singulariza, mas como ser-no-mundo" (HEIDEGGER, 1998a, p. 253).

Heidegger não se utiliza dos termos sujeito, homem, indivíduo, subjetividade, em seu pensamento, primeiramente por serem termos que já carregam em si significados históricos de longa data, e principalmente por sugerirem uma ideia contrária a que Heidegger queria expressar. Para se compreender a perspectiva heideggeriana da alteridade, torna-se necessário desconstruirmos a ideia de sujeito enquanto substância, uma vez que esse termo guarda uma herança da tradição.

O autor dedicou-se a investigar a questão do ser e assim devolve ao ente seu lugar diferenciado em relação ao seu ser. E é justamente devido a essa diferenciação que é possível ao ente que nós somos, o ser-aí, colocar em questão o sentido do seu próprio ser, do ser dos entes intramundanos e do ser dos outros. Este ente, que é ser-aí (dasein), diz Heidegger, "somos nós mesmos" e o ser deste ente "é sempre e a cada vez meu" (HEIDEGGER, 1998a, p. 77). Se o ser é a cada vez meu, isto significa que, a cada momento, este ser-aí tem que se haver com seu ser. Esse movimento constante que o ser-aí realiza, que evidencia que o seu ser "está sempre em jogo" (HEIDEGGER, 1988a, p. 77), retira de imediato qualquer 
entendimento do homem enquanto essência ou substância que permanece. Assim, a essência é a própria existência onde esse movimento se dá, portanto, não há uma essência prévia, anterior a qualquer experiência.

A partir desses esclarecimentos iniciais, podemos entender a alteridade como sendo um fenômeno existencial cuja condição de possibilidade de acontecer se funda ontologicamente. Ou seja, o sentido psicológico, ôntico, de encontro entre homens, só é possível porque desde sempre o homem é um ente cujo modo de ser é sempre já no mundo junto com os outros. Podemos dizer assim que a experiência cotidiana é sempre em relação, num sentido ontológico, na medida em que não é possível ao homem existir fora da convivência. Eu e os outros formam uma relação diferenciável, mas indissociável, entre entes cujo modo de ser se apresenta como ser-aí, ou seja, lançado às possibilidades num mundo compartilhado. Heidegger nomeia essa indissociabilidade, de ser-no-mundo-comoutro (HEIDEGGER, 1998a, p. 164).

E mesmo nas situações em que o ser-aí experiencie o ser-com ao modo do simplesmente dado, ou seja, igualando o modo da convivência ao modo como se aproxima dos entes intramundanos, isso não o isenta de ser ontologicamente já aí junto com os outros. E justamente por essa condição ontológica que lhe é possível conviver nessa modalidade.

Podemos, assim, afirmar que a alteridade é constitutiva da existência, e mesmo nos casos de isolamento imposto ou voluntário, trata-se ainda de modalidades do ser-com-outro, que podem se mostrar mais ou menos restritas, quanto em maior ou menor grau de liberdade existencial se encontrarem.

\section{A Co-Existência dos Outros}

Como já dito anteriormente, Heidegger não se dedicou ao tema dos outros de modo especial, mas, no entanto, o assunto sobre "os outros" está presente o tempo todo em Ser e Tempo. Vamos nos ater especificamente ao parágrafo 26 desta obra, onde Heidegger é mais explícito quanto à sua concepção sobre este tema.

Primeiramente, o título do parágrafo 26 já anuncia de onde Heidegger parte para explicitar seu entendimento. Para o autor, os outros são co-existentes ao ser-aí. Isso quer dizer que não há um eu e depois um outro. A convivência originariamente se dá sempre junto com os outros.

Heidegger inicia este parágrafo, esclarecendo o quanto o ser-aí dos outros se dá ao mesmo tempo em que o ser-aí lida com os utensílios à mão no mundo. E mesmo que nesta manualidade não esteja tematizada a presença desses outros, não quer dizer que eles não 
estejam presentes. Ele dá alguns exemplos para evidenciar essa coexistência:

\begin{abstract}
"o campo por onde passamos lá fora, mostra-se como o campo que pertence a alguém, que é por ele mantido em ordem; o livro usado foi comprado em tal livreiro, foi presenteado por (...) o barco ancorado na praia refere-se a um conhecido que nele viaja ou então um barco desconhecido mostra outros" (HEIDEGGER, 1998a, p. 169).
\end{abstract}

Heidegger parece mostrar que os outros estão sempre juntos ao seraí de um modo diferente dos entes intramundanos, ou seja, o modo de ser dos outros que vêm ao encontro dentro do mundo, aparece segundo o modo de ser-no-mundo, mesmo que de modo oculto. Assim, o campesino, o livreiro, o viajante são entes cujo ser também está em jogo e que lidam com o campo enquanto campo, livro e barco, só que em sentidos diferentes daqueles que os usufruem.

Mas ainda resta a possibilidade de se entender o encontro com os outros como sendo algo que se dá posteriormente ao "eu", como se pudéssemos passar do estado do eu ao encontro com os outros. Heidegger, então, afirma: "os outros não significam todo o resto dos demais além de mim, do qual o eu se isolaria" (HEIDEGGER, 1998a, p. 169), ou seja, pelo contrário, os outros constituem o "eu", numa relação de indissociabilidade. Por isso afirma que o ser-aí é em sua essência ser-com-os-outros, pois se o ser-aí é ser-no-mundo, mundo aqui então, adquire o sentido de mundo compartilhado com os outros (HEIDEGGER, 1998a, p. 170). Mas aqui cabe atenção no sentido de que mundo compartilhado não quer dizer um espaço com um grupo de pessoas, pois mundo é relação de sentidos. O que se partilha junto com os outros é uma rede significativa de sentidos, na qual se encontra uma progressão infinita de "outros" que a constituem.

Mas como se dá o encontro com os outros? Heidegger é incansável em explicitar que esse encontro com os outros se diferencia da relação que o ser-aí estabelece com os entes intramundanos, que possui o modo de ser da manualidade. Mas esse encontro com os outros se dá a partir das ocupações mundanas:

\footnotetext{
"De início e na maior parte das vezes, o ser-aí se entende a partir de seu mundo e a co-presença ${ }^{1}$ dos outros vem ao encontro nas mais diversas formas a partir do que está à mão dentro do mundo" (HEIDEGGER, 1998a, p. 171).
}

Importante retomar este a partir do que. É que os outros não chegam ao ser-aí como pessoas simplesmente dadas. O encontro acontece a partir de uma situação, emerge do mundo. Cada presença de "um outro" se dá como um modo de ser. E como tal, a co-existência dos outros só pode então ser apreendida por um ente que possui 0 
mesmo modo de ser-no-mundo, ainda que essa apreensão se dê na maioria das vezes de modo impróprio.

Assim, só se pode ser visto por outro ser-aí. As coisas, os animais, as plantas, não nos vêem, porque sendo seu modo de ser simplesmente dado, não lidam com os outros entes enquanto entes. Por não serem existentes, a relação de sentido com o mundo é pobre ou inexistente (HEIDEGGER, 2003, p. 207), nem estão presentes a compreensão e disposição, estruturantes da abertura do ser-aí, que é formador de mundo. Por isso pode-se dizer que numa relação entre co-existentes, há uma experiência de exposição mútua. E justamente por essa exposição acontecer independente da vontade, já que ser é aparecer, que diversos adoecimentos podem se dar, como sendo modos restritivos de se experienciar essa exposição.

Outro ponto importante que pode gerar equívoco é o entendimento de ser-com enquanto uma propriedade do ser-aí, como se fosse uma característica ôntica da espécie humana. Heidegger chama a atenção para este fato do seguinte modo:

\begin{abstract}
"se a frase: 'o ser-no-mundo do ser-aí se constitui essencialmente pelo ser-com', quisesse dizer isto, então o ser-com não seria uma determinação existencial que conviria ao ser-aí segundo o seu modo próprio de ser. Seria uma propriedade que, devido a ocorrência dos outros, introduzirse-ia a cada vez." (HEIDEGGER, 1998a, p. 172).
\end{abstract}

Somente a partir do entendimento da co-existência dos outros enquanto constitutivo da existência do ser-aí, pode-se compreender que mesmo quando se encontra sozinho ele ainda é ser-com. 0 estar-só aparece então como uma modalidade do ser-com-outro, como afirma:

"mesmo o estar-só do ser-aí é ser-com no mundo. Somente
num ser-com e para um ser-com é que o outro pode faltar. O
estar-só é um modo deficiente do ser-com e a sua
possibilidade é a prova disso" (HEIDEGGER 1998a, p. 172).

O estar-só não se refere tão somente ao isolamento, mas à experiência de solidão, que pode aparecer também na companhia de muitos homens. É que o estar entre os outros pode acontecer como uma co-existência ao modo da estranheza e da indiferença (HEIDEGGER, 1998a, p. 172). Assim, tanto a falta, como a ausência, são modos de presença e não seu oposto. 


\section{Mundo Compartilhado e clínica em grupo}

A clínica em grupo é uma modalidade de psicoterapia marcada principalmente pela experiência da convivência. É pela presença dessa característica constitutiva que os modos de ser-com-o-outro tendem a se tornar visíveis mais rapidamente do que em outras modalidades psicoterápicas. Se, por um lado, isso pode parecer excelente pela oportunidade que oferece de trabalho terapêutico, por outro, justamente essa condição de exposição dos modos de ser-com, que se dá com menos controle, é que pode afastar a escolha imediata por esse tipo de psicoterapia.

O entendimento de que o homem é um ente cujo modo de ser só acontece no mundo compartilhado com outros, ou seja, de que ele nada é separado do mundo que o constitui, implica que não há uma identidade anterior ou exterior às experiências relacionais. A cada relação, o ser-aí tem que se haver com seu modo de ser nela, ainda que, na maioria das vezes, de modo não temático. Isto significa que, apesar desse modo da convivência poder se repetir em várias outras experiências relacionais, não há nada substancial que determine essa repetição. O que se pode observar é uma determinada tonalidade afetiva que abre aquele modo de ser, repetidamente, e para que outro modo possa se manifestar é preciso uma modificação daquela tonalidade.

Na convivência em grupo, o esforço em sustentar um específico modo de ser, ou seja, uma identidade estável, diante de tantas convocações relacionais, se torna geralmente maior do que num encontro individual, uma forma radical desta dificuldade, em que 0 esforço se torna insuportável, é a chamada "fobia social". Em um encontro psicoterapêutico individual, a possibilidade do cliente se proteger e controlar a exposição é maior, pois, parte-se, inicialmente, de temas escolhidos por ele. É mais fácil desviar ou adiar o "poder ser tocado". No grupo, não. Ninguém sabe qual assunto será tratado, nem como cada um será afetado e corresponderá a ele. Tanto os participantes, quanto o terapeuta têm que lidar com as diversas solicitações identitárias que ocorrem, sem que haja a possibilidade de controlar o modo de corresponder a elas. No entanto, é justamente por essa diversidade que aparece e evidencia o quanto o ser-aí está em jogo no existir, que a psicoterapia grupal alcança possibilidades terapêuticas importantes. Estar em grupo pode intensificar o risco de exposição de nosso ser-aí, pois há mais situações de atrito que demandam posicionamentos. Mesmo quando algum participante escolhe estar de modo indiferente na sessão, isso, frequentemente, leva o grupo a fazer provocações que acabam revelando a indiferença como um modo de tocar e ser tocado, de ser-com-o-outro, que o participante pode reconhecer em outras situações semelhantes do seu cotidiano. 
Depois de algum tempo de convivência com o grupo, a maioria dos participantes desenvolve a experiência de pertencimento ao mesmo. Esse clima de familiaridade, que favorece o aprofundamento das relações estabelecidas, diminui o desconforto da tensão que se dá pelo esforço de conciliar tantas identidades. O tempo de convivência oferece a possibilidade dos participantes criarem identidades correspondentes àquele grupo. São modos de ser-com que se repetem, se estabilizam, permitindo um certo descanso quanto a ter que controlar atentamente o modo de se relacionar com aquelas pessoas. É possível que seja exatamente por isso que a entrada de um membro novo seja desconfortável, pois obriga o grupo a ter que se haver com essa identidade já estabelecida. Há grupos que podem lidar com o desconforto de maneira hostil ou no extremo oposto, de modo excessivamente acolhedor e permissivo. Vencer esse estado inercial é importante para que não se cristalizem determinados modos de ser-com no grupo, o que traria restrição da mobilidade existencial. Assim, ao invés do grupo ser uma instância propiciadora de transformações, tornar-se-ia impeditivo de qualquer movimento, em nome da manutenção do próprio grupo.

Esse tempo de familiarização, que, como dito acima, favorece o estabelecimento de determinadas identidades estáveis no grupo, é o que, muitas vezes, motiva o próprio grupo a diminuir o contato com outros espaços de convivência. Pois, com frequência, torna-se uma tarefa pesada para o grupo ter que conciliar identidades diversas, ou, para dizer em uma linguagem fenomenológica, manter-se aberto para diferentes possibilidades de ser. Se isso ocorre prematuramente, antes que o grupo tenha essa tessitura um pouco mais estruturada, a possibilidade do grupo se romper é maior, por não ter condições de suportar a tensão que se instaura diante da necessidade de corresponder às demandas distintas e, às vezes, contraditórias, de espaços existenciais heterogêneos.

Como veremos a seguir, Heidegger denominou como modos do "cuidado" (Sorge) a esses modos de convivência cotidiana. Diferente do entendimento do senso comum, em que o cuidado é assimilado à ideia de zelo, atenção, cautela etc, o cuidado precisa ser entendido aqui ontologicamente, como condição de possibilidade para o aparecimento dos comportamentos ônticos, qualificados cotidianamente de cuidadosos ou descuidados.

\section{Cuidado}

O ser-aí mantém com os outros entes, sejam intramundanos ou não, uma relação de cuidado. Significa dizer que esse modo de ser do seraí, que é um modo de ser-no-mundo junto com os outros, caracteriza-se essencialmente por desvelar o sentido dos entes que 
vêm ao seu encontro. Assim, o ser-aí está sempre numa relação de cuidado, seja consigo mesmo, seja com os outros ou com as coisas, pois ser si mesmo não é, senão, realizar seus modos de ser-com.

O desvelamento de sentidos, que é o próprio existir, pode se dar de dois modos, não excludentes ou alternativos: o modo da "ocupação" (Besorgen), quando o ser-aí se encontra numa relação com os entes cujo modo de ser é simplesmente dado, e o modo da "preocupação" (Fursorge), quando ele se encontra numa relação com entes cujo modo de ser é como o seu, ser-aí.

A preocupação, que também deve ser entendida ontologicamente, pode se mostrar deficiente, o que caracteriza o modo mais comum que o ser-aí mantém junto aos outros, como afirma Heidegger:

\footnotetext{
"o ser por um outro, contra um outro, sem os outros, o passar ao lado um do outro, o não sentir-se tocado pelos outros são modos possíveis de preocupação. E precisamente estes modos, de deficiência e indiferença, caracterizam a convivência cotidiana e mediana de um com outro." (1998a, p. 173).
}

Esses modos indiferentes de convivência podem facilmente sugerir que a relação do ser-aí com outros entes que são dotados do mesmo modo de ser, possa se dar ao modo da ocupação. Heidegger nos chama a atenção de que embora possa parecer insignificante, ontologicamente a diferença é essencial, pois lidar de modo indiferente com uma coisa é bem diferente de não sentir-se tocado por um ente da convivência cotidiana. Aqui o que aparece como essencial é que, para um ente cujo modo de ser está sempre em jogo, seu ser se expõe na convivência de uns com os outros. O que não ocorre com os entes intramundanos, cujo modo de ser já é dado, pois por não serem constituídos pela compreensão, nem se pode dizer deles que são indiferentes.

A preocupação na sua modalidade positiva, transita entre duas posssibilidades: a preocupação substitutivo-dominadora e antepositivo-liberadora, podendo aparecer de inúmeros modos mistos.

No modo da preocupação substitutivo-dominadora, a convivência se mostra de uma maneira tal que o outro o substitui tomando-Ihe o lugar nas ocupações cotidianas. Assim, este se retrai e só retorna quando a ocupação se lhe é oferecida de modo pronto. Nessa modalidade de convivência, aparece a dependência como modo de ser, e a dominação pode se dar de modo encoberto para o dominado, pois o domínio também pode acontecer de modo silencioso (HEIDEGGER, 1998a, p. 174). É um modo do cuidado que convida à desoneração do peso da sua existência de ambos os lados. Assumindo as ocupações alheias, há um desencarregar-se das próprias, mas trazendo sensação de peso na existência. Na outra 
ponta, em que se permite que o outro o substitua, há também um desencarregar-se, mas que pode remeter o ser-aí para um outro tipo de peso, o tédio.

Interessante notar que esse modo do cuidado, substitutivodominador, na clínica, aparece como sendo o pedido mais comum do grupo ao terapeuta: que o grupo seja tutelado por ele. Paradoxalmente, são exatamente desses modos relacionais, frequentes no seu cotidiano, dos quais desejam se afastar ou modificar.

Principalmente no início, quando o grupo ainda está se apropriando do processo psicoterápico, é frequente que os olhares dos participantes estejam sempre dirigidos ao terapeuta, na espera da resposta final. E essa resposta pode ser ouvida de muitos modos além do verbal, pois quem não quer a aprovação do olhar do terapeuta? Conquistar autonomia num grupo psicoterapêutico não é tarefa fácil não. Suportar o desconforto da solidão das decisões diferentes, não esperadas, exige firmeza.

No outro extremo, que Heidegger caracteriza como sendo antepositivo-liberadora, a convivência se mostra mais livre, na medida em que o outro se antepõe e, não, substitui o ser-aí. Por anteposição deve-se entender que o outro procura colocar-se de um modo tal que a convivência libere o ser-aí na sua existência. Aqui não ocorre retraimento, muito pelo contrário, há um convite para ampliação das possibilidades de existir, para assumir a própria existência.

No que diz respeito à clínica, seja na modalidade individual ou em grupo, pode-se dizer que o vínculo psicoterapêutico deve se aproximar do modo de convivência antepositiva-liberadora, sem, no entanto, excluir a possibilidade da relação se dar ao modo da convivência substitutiva. É preciso não esquecer que há uma tendência, sempre presente, da convivência se mostrar substitutiva. Desse modo o psicoterapeuta mantém-se atento para que o vínculo não se fixe numa única maneira de se dar a fim de que nessa mobilidade, a convivência se estabeleça do modo mais livre possível. $\mathrm{Na}$ clínica em grupo ainda há uma especificidade importante do cuidado. É que o grupo tende a assumir uma postura conselheira, tutelar, diante do sofrimento do outro, próxima a grupos de ajuda mútua. Nada contra esse posicionamento, que é necessário em grupos dessa natureza. Mas um grupo de psicoterapia guarda uma diferenciação importante de ser apontada. Em grupos de ajuda mútua, há um comportamento esperado a ser alcançado pelos membros do grupo, e a atmosfera de acolhimento é predominante nos encontros. Devido a isso, são bem vindas sugestões para que haja modificação de comportamento, pois esse é seu objetivo e o motivo que mantém os participantes naquele grupo. 
Na psicoterapia de grupo, embora haja momentos em que a troca de informações sobre a resolução de questões cotidianas seja inevitável e por vezes até favorável, essa não deve ser a tônica do grupo por comprometer sua característica essencial de espaço de negatividade. Embora seja tentador, é necessário que o grupo não descanse no conforto de respostas prontas às questões que eles trazem. Necessário porque é justamente desse conforto que já não oferece mais direção, que os adoecimentos silenciosamente emergem.

Um caminho possível é que a cada sugestão dada por algum participante, o terapeuta possa remetê-la de volta investigando a intenção de quem a ofereceu, ou perguntando a quem recebe como vê e como se sente diante da mesma, enfim, o que importa é manter o fio da sessão de tal modo que os participantes possam questionar exatamente esses modos cotidianos, sedimentados, a fim de acolher o que lhe for mais próprio, e, não, o que se espera que ele reproduza. Dessa maneira, o terapeuta mais do que nunca precisa estar atento para que ele também não se deixe levar por orientações de mundo que, ao invés de ensejar apropriação, encubra mais intensamente os sentidos destas experiências.

\section{Cotidiano Psicoterápico - diálogo}

É comum se ouvir que "é bom participar de um grupo", "trabalhar em grupo", que "os grupos são terapêuticos para as pessoas". São afirmativas que partem de um entendimento já tomado como inquestionável, de uma certa positividade prévia, de que todos precisam aprender a conviver. Sem negar o valor que uma convivência grupal traz, ela ainda não é o bastante para justificar ou sustentar a necessidade de se procurar uma psicoterapia em grupo.

Há algo que caracteriza um encontro psicoterapêutico e que o diferencia dos encontros comuns com os outros no cotidiano. Como ponto de partida desta diferença, temos as tonalidades afetivas que predominam nas sessões.

Para Heidegger, a disposição afetiva (Befindlichkeit) faz parte da constituição ontológica do modo de ser do homem: a existência. Por isso, o existir encontra-se sempre afinado numa determinada tonalidade afetiva (Stimmung). Se "tonalidades afetivas são jeitos fundamentais nos quais nos encontramos de um modo ou de outro no mundo" (HEIDEGGER, 2003, p. 81), quais as que aparecem mais frequentemente na psicoterapia? Certamente não são apenas as cotidianas, já que quem se dirige para a psicoterapia encontra-se em geral em um clima de desconforto existencial. É justamente pela quebra dos modos cotidianos de conviver que a psicoterapia aparece como espaço de cuidado. Portanto, aquele que procura um psicoterapeuta, precisa vencer certa inércia, que faz parte dos modos 
costumeiros de se lidar com as dores existenciais, e esperar da psicoterapia a possibilidade de sentir algo diferente do que experimenta.

No horizonte da produtividade, da técnica, na qual nos encontramos, o desconforto pode se manifestar como vergonha, como fracasso das estratégias de cuidar de si, uma vez que o "estar bem" é a atmosfera idealizada a ser alcançada e passível de ser mantida pelo controle individual. Nessa perspectiva, a psicoterapia pode justamente atender à convocação de habitar o lugar de estratégia de manutenção do bem-estar. Segundo Heidegger (2002), não nos é possível escapar ao mundo técnico no qual estamos imersos, mas podemos nos interrogar acerca do mesmo. Sendo assim, à psicoterapia de inspiração fenomenológica caberá o esforço de manter a tensão diante dos modos, já sedimentados, de corresponder a esses apelos a fim de abrir modos singulares que possam transformar espaços existenciais de convivência.

Outra caracterização importante diz respeito ao diálogo terapêutico propriamente dito, que em muito se diferencia dos diálogos cotidianos. Nestes, nossa atenção se dirige para o conteúdo do que se fala e esses conteúdos são tomados como fatos em si, objetivos, como que independente de quem fala. $E$ os diversos modos de interagir se dão a partir desses conteúdos que têm a missão de informar o que cada um quer dizer para o outro, partindo-se do senso comum. Nessa perspectiva toma-se o mundo como algo já dado e prévio à experiência, e quem dialoga são sujeitos em si mesmos. A esse posicionamento Husserl (1989) denomina de atitude natural, na qual não se leva em conta que o sentido da existência está em jogo naquela experiência porque ela é ser-no-mundo, portanto jamais podendo ser tomada como algo separado do mundo. Para que o diálogo terapêutico em grupo não se torne uma mera conversa, é necessário cuidado. Isso não significa que a terapia se oponha ao diálogo cotidiano, pois é desde que se parte, mas com uma escuta específica, atenta.

No diálogo psicoterápico na abordagem fenomenológica, a atitude não poderia deixar de ser fenomenológica. Essa atitude implica em primeiro lugar tomar o mundo como fenômeno. Assim, o conteúdo que é falado nas sessões não é fato, simples acontecimento. São experiências dotadas de sentido, e, portanto, necessitam de uma aproximação tal que permitam o desvelamento desses sentidos que não são captados pelo olhar imediato, por se mostrarem de modo opaco na experiência cotidiana.

Explicitando um pouco mais, o que está velado é o horizonte, o contexto, que abre uma certa constituição de sentido da experiência. Assim, neste diálogo terapêutico, ouve-se "mais" do que o senso comum, pois se compreende o que é falado a partir do contexto de sentido. Significa identificar o contexto no qual aquela experiência 
emerge enquanto fenômeno. Na medida em que esse contexto é tecido pelo mundo, o que vem à luz são, de início e na maior parte das vezes, orientações sedimentadas, ou seja, modos impessoais de correspondência aos apelos do mundo. Portanto, a partir desse desvelamento de sentidos, o diálogo terapêutico dirigir-se-á a tematização dos mesmos. O que se tematiza em primeiro lugar, é o reconhecimento do quanto essas orientações sedimentadas determinam a experiência do ser-aí. A partir disso é possível surgir algum espaço de singularização existencial. Este movimento pode convidar o ser-aí a uma apropriação de sua existência, que, de início e na maior parte das vezes, se mostra distraída. Pode-se dizer que o ser-aí vive adormecido no seu existir e o diálogo terapêutico pode acordar um "quem" que dorme.

Sendo assim, para a psicoterapia em grupo, junto ao que é dito, a sessão se ocupa dos modos da fala, dos modos de agir, dos modos de escutar, enfim, dos modos de ser em relação que os participantes travam entre si e com o terapeuta. Yalom denomina esse movimento de "foco no processo" (YALOM, 2008, p. 126), onde o terapeuta se ocupa de explicitar, a partir do relato de alguém, o que esse modo de dizer revela sobre esse modo de encontrar o outro. Também se ocupa de observar e trabalhar com o grupo o impacto dessa fala sobre eles: como se sentem? O que diz de vocês o modo como escutam essa fala?

E além de focar esses dois movimentos (como fala - como escuta), o terapeuta ainda volta sua atenção para a sequência das falas do grupo, na qual se revela não só o modo relacional, mas desvela-se $o$ sentido dessas falas em grupo que emerge daquela experiência especifica ("o quê contamos hoje no grupo?"). Essas questões são apenas possíveis de serem levantadas porque o caráter do vínculo que é tecido entre os participantes do grupo é terapêutico, como desenvolveremos a seguir.

\section{A Questão do Vínculo}

Na clínica psicológica na abordagem fenomenológico-existencial, a relação terapêutica assume papel principal, pois é nesta onde todo o processo se dá. No que diz respeito à clínica em grupo, além da relação com o terapeuta, há que se dedicar atenção simultânea para a relação que ocorre entre os participantes do grupo, sem o qual essa investigação perderia seu propósito.

Mas além das relações que ocorrem no processo psicoterapêutico propriamente dito, também está presente o modo de se relacionar que os participantes travam com as pessoas de sua convivência cotidiana e essas relações não guardam entre si nenhuma diferença quanto ao grau de relevância no processo. Ou seja, as relações da 
infância, ou as relações atuais, mas "externas" ao grupo, não são tomadas como sendo as principais, ou causais em relação às do grupo. Sendo assim, numa psicoterapia de grupo de inspiração fenomenológica, não faz sentido tomar as relações que ocorrem no grupo como sendo "projeções" das relações outras que os participantes mantenham além ou anteriormente ao grupo. As repetições que possam ocorrer nos modos de ser em relação com os outros, e que sejam observadas pelo participante ou pelo grupo, são assim entendidas como um "estar amarrado numa determinada afinação" (HEIDEGGER, 2001, p. 186) que só permite que o ser-aí veja aqueles determinados fenômenos, e não outros. Aquilo para o qual ele está atento, que é o que se repete, revela um modo de ser, e encobre outros que só poderão ser revelados quando o ser-aí se encontrar em uma outra tonalidade afetiva. Em diálogos com Boss, quando este pergunta sobre o fenômeno da transferência que é tão conhecido na psicanálise, Heidegger afirma que:

\footnotetext{
"nada precisa ser transferido, pois em cada caso, a afinação a partir da qual e de acordo com a qual tudo que vem ao encontro só pode mostrar-se dessa maneira, já está sempre aí. Dentro de cada afinação também uma pessoa que nos encontra mostra-se para nós de acordo com esta afinação" (HEIDEGGER, 2001, p. 187).
}

O trabalho terapêutico, nesta perspectiva, assume então contornos diferentes pela concepção de relacionalidade de onde ele parte, pois a compreensão deste fenômeno, por apresentar variações, oferece inúmeros caminhos para uma prática psicoterápica. Alguns autores irão auxiliar na explicitação da especificidade desse vínculo na clínica grupal, como será mostrado a seguir.

Para Cohn (2007, p. 55), o terapeuta de grupo é um membro do grupo. Essa afirmativa aponta uma diferença significativa da abordagem fenomenológica na clínica grupal, em relação aos processos psicoterapêuticos grupais tradicionais. Diz respeito à inclusão do psicoterapeuta no processo, ou seja, este jamais pode estar fora ou isento do que se passa no grupo. E não poderia ser de outro modo, pois para a fenomenologia, qualquer busca de neutralidade não é possível. Esta impossibilidade se deve ao fato de que o ser-aí é sempre em situação, não havendo o "fora" dela. Se o ser-aí é ser-no-mundo, sempre em relação com os outros, com as coisas, enfim, está sempre envolvido em tudo o que lhe acontece, ele é constituído e transformado a partir de suas relações. Sendo assim não há um estado anterior às relações, mas sempre um a partir de, na qual se constituem modos diferentes de estar em relação.

Na situação psicoterápica, ao fazer uma observação no grupo, o terapeuta parte sempre de alguma tonalidade afetiva, que é uma corespondência ao clima grupal. Não há como ele se deslocar para um 
"ponto zero", isento, de onde ele poderia emitir suas percepções, pois elas surgem do contexto ao qual o terapeuta também o constitui. $O$ simples fato de estar presente ao grupo, já modifica sua percepção e vice-versa, pois o grupo também se modifica tanto com a ausência quanto com a presença de quem quer que seja na sessão.

Spinelli também aponta para a importância do modo da relação terapeuta-paciente como sendo um diferenciador de outras abordagens:

\begin{abstract}
"Diferente das outras abordagens na qual o foco e interesse estão no mundo subjetivo do cliente, na abordagem existencial reside na inter-relação entre terapeuta e cliente como foco da descrição da visão de mundo deste. Nesta diferença o terapeuta existencial não pode excluir sua presença do processo nem estar preso a um modo particular de estar presente" (SPINELLI, 2007, p. 103).
\end{abstract}

O autor Fiorini também compartilha essa proposta, mas defende a ideia de que essa inclusão do terapeuta como membro do grupo, se dê de modo seletivo, já que sua participação no grupo tem uma finalidade diferenciada dos demais:

\footnotetext{
"Questionamos, nesse sentido, as dissociações tradicionais entre a técnica e a influência pessoal do terapeuta, entendendo que a inclusão seletiva do terapeuta como pessoa converte-se em componente decisivo da técnica psicoterapêutica" (FIORINI, 1978, p. 23).
}

Goldberg (1973) afirma que na congruência empática entre paciente e terapeuta, sem o qual a terapia não pode ocorrer, o terapeuta partilha da experiência do paciente não como se fosse sua própria, mas como sua mesmo. Contudo, que isso se dê sem que ele se perca de si mesmo. Além disso, o autor acentua que o fato de que o terapeuta possa participar como um membro, mostra ao grupo que ele é capaz de cometer erros, de apresentar fraquezas, mas que, sobretudo, sua presença não é uma representação, um personagem invulnerável. Portanto não cabe a ele nenhum papel superior ao grupo, de máximo saber, de julgamento, ou de observação passiva.

\title{
8 Vínculo entre os membros do Grupo
}

Quem olha, olha de algum lugar, para um outro lugar.

Sempre lançado numa certa direção, o olhar é situado, se dá numa certa perspectiva, jamais acontece na neutralidade. Mesmo quando somos observadores, esse lugar de onde observamos não é vazio de sentido. É pleno de referencias, experiências. Podemos até buscar um 
olhar que não seja julgador, mas não há a possibilidade de ser como um ponto fora da experiência.

$\mathrm{E}$ ao mesmo tempo em que olhamos, somos olhados. E nesse encontro sem precedência, constituímos e somos constituídos pelos outros. Esse outro, tanto pode ser imaginado como tocado, mas não há olhar sem a presença emocionada desses tantos outros que nos acompanham. Assim, cada um de nós é um olhar lançado no mundo, atravessado e construído por este, por sermos também visíveis ao mundo.

Essa condição de visibilidade, que nenhum de nós pode se apartar, transcende o órgão da visão, pois também olhamos através da palavra, do pensamento, dos gestos de nosso corpo inteiro. E nos diversos sentidos que um olhar pode se manifestar, como o de acolhimento, de vigilância, de advertência, de proteção, ele ainda pode acontecer ao modo da tristeza, da alegria, do alívio, da indiferença. Ou seja, é modalizado, colorido afetivamente, revelando o modo de ser do ser-aí. Fechar os olhos para não ver torna-se assim, o modo de olhar que está presente naquele contato. Fechamento, negação, exclusão, é também um modo de olhar. E esse modo diz de nós mesmos, diz do modo como somos afetados pelo mundo e como nos relacionamos com os outros. É que ver é olhar para tomar conhecimento, e muitas vezes é justamente disto que desviamos o olhar, pois, ver confere existência.

O sentido de reconhecimento que um olhar pode conferir, abre a possibilidade de mudança numa relação, pois é um olhar de respeito (a palavra respeito vem de $r e=$ de novo e spicere $=$ olhar, considerar). Considerar pode ser entendido então, como olhar alguma coisa na sua relação com o contexto mais amplo.

Sentir-se desrespeitado, então, é o mesmo que sentir-se não visto, e se não sou visto a sensação é de não existência. E sendo assim, como pode ser reconhecido? Diante dessa falta de reconhecimento, dessa sensação de exclusão, muitas vezes ser violento (latim violentia = tratar com força contra o direito alheio) é uma das possibilidades para sair do anonimato, da negação do olhar do outro. Quem sabe assim pode-se garantir que existe, mesmo que seja ao modo do sofrimento?

Olhar para tomar conhecimento. Reconhecimento, conhecer de novo e a cada vez. Para ver de um outro modo e assim poder descobrir o que antes ainda não havia sido possível ver. Não é que já está lá no outro ou em mim mesmo o que me falta ver. Mas é exatamente no modo de olhar que se abre o novo de mim e do outro. Nasce deste encontro, desta abertura, desta disponibilidade. Olhar para ver. Ver o que se mostra, tal como é.

Ricoeur (2009) aponta o respeito como sendo o que estabelece a relação fundamental da alteridade. $O$ autor sugere que ao invés da empatia, que Husserl (2006) propõe como sendo foco central da 
intersubjetividade, o respeito seja mais fundamental que ela, uma vez que a empatia (Einfuhlung) é por demais contaminada por "tendências românticas", o que dificultaria a compreensão de determinados sentimentos como, por exemplo, o ódio, ou a indiferença. Por outro lado, parece que o autor, por não distinguir claramente a diferença entre empatia e simpatia, situa o respeito como sua oposição:

"O respeito aprofunda a distância fenomenológica entre os seres, pondo o outro ao abrigo das invasões da minha sensibilidade indiscreta: a simpatia toca e devora o coração, o respeito observa de longe" (RICOEUR, 2009, p. 323).

No entanto, é o respeito que oferece as condições para que o ódio tanto quanto a alegria possa aparecer. O ódio seria assim, uma modalidade do respeito, um "respeito despeitado" (RICOEUR, 2009, p. 325).

Para o autor, os sentimentos são manifestações sentidas dos vínculos ${ }^{2}$, e permite que o ser-aí tenha pertença no mundo: "enquanto a representação nos opõe aos objetos, o sentimento atesta a nossa afinidade, coadequação" (RICOEUR, 2009, p. 295). Ricoeur denomina essa ligação do ser-aí com o mundo de vínculo conatural, e este acontece de modo silencioso (RICOEUR, 2009, p. 296). Interessante esse termo silencioso, pois esclarece que a tonalidade afetiva não se dá pela escolha voluntária do ser-aí, muito pelo contrário, é silenciosamente que o ser-aí, que é de abertura para o ser, se encontra já desde sempre em relação com os entes no mundo.

Partindo dessa noção do respeito como sendo o fundamento dos vínculos, no que diz respeito aos vínculos entre os membros do grupo, não é diferente. O modo como cada participante se manifesta no grupo, "diz" do seu modo de se vincular no mundo. Mas há um aspecto importante, senão essencial, quanto a esses vínculos: é seu caráter que se anuncia antes mesmo dos participantes se encontrarem pela primeira vez.

O vínculo psicoterapêutico já se inicia com seu caráter definido: é terapêutico. E quando os participantes chegam à psicoterapia, se deparam com um grupo que foi estabelecido alheio à sua escolha. Não é que sejam obrigados a se relacionar, pois todos são livres para ficar ou sair do grupo, mas se entregar ou restringir-se nesses laços é sempre o que estará em jogo nas sessões. $E$, não raro, esperam a tutela do terapeuta, de modo que este possa dar a regra para esse lançar-se, como se o modo de relacionar-se não constituísse a psicoterapia em grupo propriamente dita.

Apesar do caráter terapêutico do grupo ser pressuposto por todos, ter esta mera informação não é suficiente para dar conta dos fenômenos 
vinculares. Faz parte do processo grupal o caráter de ter que ser reconquistado a cada momento, pois uma relação terapêutica não é dada previamente à experiência do estar junto. Entender, saber, conscientizar se mostram sempre restritos diante dos fenômenos relacionais que estão presentes em uma sessão. É preciso uma experiência própria das tonalidades afetivas em jogo. Sendo assim, ao longo de toda a vida do grupo, essa é uma questão que jamais se esgota, porque esse vínculo terapêutico se afasta e se aproxima o tempo todo, nos diversos modos vinculares possíveis. $E$ é nesse aproximar e afastar que a terapia se desenrola, pois é o que permite experienciar a identidade e a diferença.

Devido a essas características do vínculo psicoterápico, é que todas as questões que surgem na sessão atravessam o grupo por inteiro, e tocam a cada um de um jeito peculiar, inclusive 0 terapeuta. Podemos investigar como cada um foi tocado por aquele tema, o que faz a partir disto, o que pensa sobre isto, mas há que se ter cuidado para não hipostasiar as possibilidades de ser que assim se mostram como algo interior, prévio ao ser-no-mundo-com. Pois, é naquela experiência que aquelas questões surgiram. $O$ fato de que certo modo de se deixar afetar se repita constantemente, seja conhecido e familiar, não significa que se imponha por determinações "internas". Tal compreensão aliena, mais do que leva a uma apropriação do modo de ser. É com aquelas pessoas, por exemplo, que o amor exigente aparece, pedindo exclusividade, sigilo absoluto. É com elas que o medo de se arriscar se levanta, pedindo asseguramento. Se é com essas pessoas nessas situações, torna-se necessário partirmos dessas relações especificas, situadas, para nos apropriarmos dos modos como correspondemos a elas e das possibilidades que, assim, realizamos e às quais, muitas vezes, nos reduzimos. Os participantes do grupo não são meros depositários de projeções das relações externas a ele. Muito pelo contrário, é na convivência com estes que se abre a chance de poder olhar os modos vinculares, que são modos de ser no mundo junto com outros.

Por isso, a cada sessão o modo como se configura o grupo depende de quem está presente nela. O clima se constitui inclusive a partir dessa presença que se diferencia constantemente. Geralmente, não é muito claro para os participantes porque determinado assunto foi possível de ser trabalhado numa sessão especifica. Torna-se necessário levar em conta quem está ali, constituindo o grupo, naquele momento. A atmosfera compartilhada abre condições para certos estados afetivos e afasta outros, permitindo que assuntos específicos possam emergir e não outros. Há sessões em que a proximidade afetiva é tão intensa que os participantes não precisam falar muito, e algo se dá no encontro que faz com que todos se sintam compreendidos e pertencentes. Não quer dizer que os problemas estejam "resolvidos", mas que diante deles os 
participantes se sentem "sobre seus próprios pés". Assim como há outras sessões em que o clima é moroso, tedioso, nas quais o grupo se sente como que diante de uma pedreira irremovível, por mais que se tente a aproximação, tudo é absorvido por um falatório inócuo.

As possibilidades descritas aqui não devem ser tomadas como estruturas universais das dinâmicas de grupo. Assim como fazer terapia individual não é garantia de aprofundamento, também não se deve atribuir à terapia em grupo garantia de melhor socialização e aprendizagem de convivência. Os dispositivos terapêuticos apenas convidam à apropriação e à desnaturalização dos modos cotidianos e sedimentados de corresponder ao mundo, ensejando, assim, o exercício da livre abertura a essas mesmas e a outras possibilidades de ser. Procuramos apenas mostrar as especificidades do dispositivo grupal, descrevendo algumas de suas características e pensando sobre o seu sentido a partir de uma compreensão fenomenológicoexistencial do homem como ser-aí. Embora, ontologicamente, não se esteja menos com-o-outro quando se está empiricamente isolado, do que quando se está em multidão, a psicoterapia em grupo pode se mostrar como um espaço onticamente privilegiado para a apropriação dos modos de ser-com-o-outro que constituem, essencialmente, 0 nosso ser-si-mesmo.

\section{Considerações finais}

A modalidade grupo requer que seu lugar nas práticas clínicas seja constantemente reconfigurado por se tratar de uma estratégia que pode perder-se de sua própria finalidade, quando atende às demandas de produtividade técnica de assistir um maior número de pessoas no menor tempo possível. A abordagem fenomenológicoexistencial, atenta ao que é mais próprio à existência, a liberdade, propõe que a modalidade em grupo seja atualmente um dispositivo para refletir sobre os modos impessoais de se corresponder às demandas contemporâneas. Refletir não é negar nem se opor a essas demandas, mas se manter desperto para tomar posição diante delas de modo mais singular. Entendemos que o trabalho psicoterapêutico em grupo pode oferecer oportunidades privilegiadas para esse tipo de experiência, por se configurar como um campo onde os modos de convivência tendem a se evidenciar mais e onde as possibilidades de controle e produtividade por parte do especialista tendem a ser menores, pelo alto grau de imprevisibilidade que uma sessão em grupo apresenta, se comparada a uma sessão individual. Não foi o objetivo deste trabalho fazer uma comparação valorativa ou privilegiar uma modalidade psicoterapêutica em detrimento da outra, mas apenas considerar os sentidos das contribuições específicas que a clínica em grupo pode trazer para as práticas psicológicas. 


\section{Referências}

BARATA, A. O outro e a relação: O contributo da fenomenologia da intersubjectividade. In: Phainomenon, Lisboa, v. Primavera/Outono, n. 16/17, p. 295-314, 2008.

$\mathrm{COHN}, \mathrm{H}$. W. Existential thought and therapeutic practice. London: Sage Publications, 2007.

DARTIGUES, A. O que é a fenomenologia? $2^{a}$. ed. Rio de Janeiro: Eldorado, 1973.

DUARTE, A. 2000: Por uma ética da precariedade: sobre o traço ético de Ser e Tempo. Natureza Humana: Revista Internacional de Filosofia e Práticas Psicoterápicas, São Paulo, v. 2, n. 1, p. 71$101,2000$.

DUARTE, A. Heidegger e o outro: A questão da alteridade em Ser e Tempo. Natureza Humana: Revista Internacional de Filosofia e Práticas Psicoterápicas, São Paulo, v. 4, n. 1, p. 157-185, 2002.

FIORINI, H. J.; PEYRÚ, G. M. Desenvolvimentos em psicoterapias. Rio de Janeiro: Francisco Alves Ed., 1978

GOLDBERG, C. The human circle: an existential approach to the new group therapies. Chicago: Nelson Hall Company, 1973.

HEIDEGGER, M. Ser e tempo - parte I. Petrópolis: Editora Vozes, 1998a.

Seminários de Zollikon. Petrópolis: Editora Vozes, 2001.

Ensaios e conferências. Petrópolis: Editora Vozes, 2002.

Conceitos fundamentais da metafísica. Rio de Janeiro:

Forense Universitária, 2003.

HUSSERL, E. A ideia da fenomenologia. Lisboa: Ed. 70, 1989.

- Meditações cartesianas: Introdução a Fenomenologia.

Madras Ed., 2006.

NUNES, B. A Questão do Outro em Heidegger. Natureza Humana: Revista Internacional de Filosofia e Práticas Psicoterápicas, São Paulo, v. 3, n. 1., 2001.

RICOEUR, P. Na Escola da Fenomenologia. Petrópolis: Ed. Vozes, 2009.

SPINELLI, E. Practising existential psychotherapy. London: Sage Publications, 2007.

YALOM, I. D. Psicoterapia de grupo: teoria e prática. Porto Alegre: Artmed, 2006.

Endereço para correspondência

Ana Tereza Camasmie

Programa de Pós-Graduação em Psicologia da Universidade Federal Fluminense -

Campus do Gragoatá - Rua Prof. Marcos Waldemar de Freitas Reis, s/n, bloco O,

sala 214, CEP: 24210-201, Gragoatá, Niterói, RJ, Brasil

Endereço eletrônico: atcamasmie@gmail.com 
Ana Tereza Camasmie, Roberto Novaes de Sá Reflexões fenomenológico-existenciais para a clínica psicológica em grupo

\section{Roberto Novaes de Sá}

Programa de Pós-Graduação em Psicologia da Universidade Federal Fluminense Campus do Gragoatá - Rua Prof. Marcos Waldemar de Freitas Reis, s/n, bloco O, sala 214, CEP: 24210-201, Gragoatá, Niterói, RJ, Brasil

Endereço eletrônico: roberto novaes@terra.com.br

Recebido em: 09/11/2011

Reformulado em: 14/07/2012

Aceito para publicação em: 24/07/2012

Acompanhamento do processo editorial: Ana Maria Lopez Calvo de Feijoo

\section{Notas}

*Doutoranda em Psicologia - Universidade Federal Fluminense (UFF), Niterói/RJ, Brasil; Mestre em Filosofia - PUC, São Paulo/SP, Brasil; Especialista em Psicologia Clínica - PUC, Belo Horizonte/MG, Brasil; Psicóloga - UERJ, Rio de Janeiro/RJ, Brasil.

**Professor Titular do Programa de Pós Graduação em Psicologia da UFF, Niterói/RJ, Brasil.

${ }^{1} \mathrm{~A}$ expressão alemã mitdasein para a qual a tradução brasileira utilizou o termo copresença, será por nós traduzida por co-existência.

${ }^{2} \mathrm{~A}$ fenomenologia que Ricoeur desenvolve sobre os sentimentos, aproxima-se da concepção heideggeriana sobre a tonalidade afetiva, como aparece no seguinte trecho: "Mas como essas qualidades (as qualidades sentidas) não são objetos em face de um sujeito, mas a expressão intencional de um vínculo indiviso com o mundo, o sentimento vai aparecer ao mesmo tempo como um colorido de alma, como uma afecção" (RICOEUR, 2009, p. 296). 